\title{
SEROPREVALENCE OF IMMUNOGLOBULIN IgG ANTIBODY RESPONSE TO PLASMODIUM FALCIPARUM MEROZOITE ANTIGENS AMONG CHILDREN IN MINNA, NORTH CENTRAL, NIGERIA
}

\author{
YAMMAN-USMAN HADIJAH ${ }^{1 *}$, OMALU CJ INNOCENT ${ }^{1}$, ABUBAKAR ABDULKADIR ${ }^{2}$, ABOLARINWA SO ${ }^{1}$, \\ EKE S SAMUEL ${ }^{3}$, OTUU A CHIDIEBERE ${ }^{4}$
}

${ }^{1}$ Department of Animal Biology, Federal University of Technology, Minna, Niger State. ${ }^{2}$ Department of Biochemistry, Federal University of Technology, Minna, Niger State. ${ }^{3}$ Department of Biology, Air Force Institute of Technology, Kaduna. ${ }^{4}$ Parasitology and Public Health Research Unit, Department of Zoology and Environmental Biology, University of Nigeria, Nsukka, Nigeria. Email: nnalude@gmail.com

Received: 02 March 2021, Revised and Accepted: 20 March 2021

\section{ABSTRACT}

Introduction: Malaria is still a major cause of severe illness which is responsible for millions of deaths, mostly in children under 5 years old. A major problem to malaria vaccine production is the identification of protective epitopes and respective protective antibody.

Objective: A cross-sectional study was carried out in a representative cohort of children in Minna aged 6 months-17 years to determine the correlation between immunoglobulin G (IgG) antibody responses to Plasmodium falciparum merozoite antigens.

Methods: Plasma samples from 93 children were exposed to Enzyme-Linked Immunosorbent Assay for the measurement of IgG antibody production against P. falciparum

Results: There was a high seroprevalence of IgG antibody against P. falciparum antigens tested with $74.20 \%$. The seroprevalence for the male category was quite higher as compared with that of the female category, though, analysis using Mann-Whitney $U$-test revealed IgG antibody response to P. falciparum infection in the male was significantly different as compared to the female category $(\mathrm{p}<0.05)$. Furthermore, the prevalence of IgG antibody against $P$. falciparum antigen increased with age, with the lowest observed in 6 months-5 years $66.66 \%$. Kruskal-Wallis $H$ test showed a non-significant difference in the production of IgG antibody against $P$. falciparum antigen between different cohorts, and no correlation exists between them ( $p>0.05)$. An evidence of more than $50 \%$ was found for the production of IgG antibody by sub-microscopic parasite. On the other hand, microscopically positive P. falciparum samples recorded more seroprevalence of $68.81 \%$ as against negative samples, though significant difference between the negative and positive P. falciparum infected samples and the production of IgG antibody was not observed ( $\mathrm{p}>0.05)$.

Conclusion: This study has demonstrated a boosting immune responses by sub-microscopic parasite and also suggests a strong relationship between production of IgG antibody and malaria transmission, rather than protective immunity.

Keywords: Antibody, Antigen, Enzyme-linked immunosorbent assay, Immunoglobulin, Malaria, Plasmodium falciparum.

(C) 2021 The Authors. Published by Innovare Academic Sciences Pvt Ltd. This is an open access article under the CC BY license (http://creativecommons org/licenses/by/4.0/) DOI: http://dx.doi.org/10.22159/ijms.2021v9i3.41268. Journal homepage: https://innovareacademics.in/journals/index.php/ijms

\section{INTRODUCTION}

Plasmodium falciparum remains a major cause of malaria which is responsible for millions of deaths worldwide with mostly children being affected. Malaria accounts for about $69 \%$ deaths worldwide among these children [1] and a total of 191 million cases and over 390 thousand deaths reported in 2016. In Nigeria, there were an estimated 33,000 malaria cases per 100,000 people, with 110,000 of these cases resulting in deaths [2]. Although, there has been a gradual decline in the prevalence of malaria among Nigerian children over the years (from $42 \%$ in 2010 to $27 \%$ in 2015), malaria remains a leading cause of death among them [2].

Due to the endemic nature of malaria in Nigeria, partial immunity to malaria is acquired. Hence, individuals living in malaria endemic areas develop naturally acquired immunity to Plasmodium spp. infections as they age, but this occurs slowly and after repeated exposure [3,4], then capability of controlling parasitemia in the blood is then developed at a later stage. Studies have shown that antibodies contribute to protection against clinical malaria due to P. falciparum. Antibodies directed against cell surface proteins of either the merozoite form of the parasite or of infected red blood cells have been shown to be important components of acquired protective immunity against malaria [5].
Meanwhile, the development of partial immunity to clinical malaria is antigen-specific, mediated by exposure to various genetically distinct parasite subpopulations, which are referred to as clones. There is usually a cross-protection conferred by antigenically similar clones [6]. In areas of high malaria transmission, residents are often exposed to a diversity of clones, which results in a rapid development of anti-malaria immunity and asymptomatic infections [7]. In areas of low transmission; however, there is a lower rate of multiclonal infections and anti-disease immunity develops more slowly [8]. This study focuses at determining the seroprevalence of immunoglobulin (IgG) antibody responses against $P$. falciparum merozoite antigens. At any rate, malaria elimination and control is important, and control measures require, in part, adequate understanding of acquired immunity and how it relates to parasite burden in the host. This study seeks to obtain information and provide baseline data on acquired immunity due to P. falciparum infection in a part of North-Central Nigeria.

\section{METHODS}

\section{Ethical approval}

Ethical approval and clearance were obtained from Niger State Ministry of Health, and Director, Primary Healthcare, Chanchaga Local 
Government, respectively. Furthermore, informed consent was obtained from the parents or guardians of children captured in this study.

\section{Sample collection}

The study was conducted in Minna, the capital city of Niger state in North Central Nigeria located at 9.62 latitude and 6.55 longitude and situated at elevation $243 \mathrm{~m}$ above sea level, covering a land area of $88 \mathrm{~km}^{2}$. It has an estimated population of 1.2 million. In this area, no fewer than 19,000 children below 5 years old, die of malaria annually, making it the region with the highest number of child deaths from malaria in the north central zone of the country [9]. This site has a tropical climate with two seasons, the rainy and the dry seasons, which start from May-October and December-March, respectively.

This is a cross-sectional study with a cohort of children between 6 months and 17 years. A total of 93 children were recruited from outpatient departments of selected healthcare facilities within the period of the study. Blood samples collected from the children were used for determination of malaria parasite status and Enzyme-linked Immunosorbent Assay (ELISA).

\section{Parasitological measurements}

For each blood sample collected, thick and thin blood smear was prepared, and then stained using Giemsa-stain technique to identify parasite density (PD) and Plasmodium species, respectively. Parasite population was obtained by counting the number of asexual parasites per 200 white blood cell (WBCs) counts and calculating parasites $/ \mu \mathrm{l}$ assuming a WBC count of $8000 / \mu \mathrm{l}$. A smear was considered negative if no parasites were seen after review of 100 high-powered fields. Parasitemia was categorized as low $(<1000$ parasite $/ \mu \mathrm{l})$, moderate (1001-10,000 parasite $/ \mu \mathrm{l})$, high $(>10,001 / \mu \mathrm{l})$, and hyperparasitemia $(\geq 100,000)[10,11]$.

\section{Measurement of IgG using ELISA}

The anti-malaria ELISA kit ab178649 from Abcam ${ }^{\circledR}$ was used following the manufacturer's instructions. All reagents, samples and controls were equilibrated to room temperature $\left(18-25^{\circ} \mathrm{C}\right)$ before use. Before assaying, all samples were diluted 1:100 with IgG sample diluent. Sample $(10 \mu \mathrm{L})$ was added to $990 \mu \mathrm{L}$ IgG sample diluent to obtain a 1:100 dilution. It was mixed gently and thoroughly. Exactly $100 \mu \mathrm{L}$ of sample was added into the 96-wells. The plates were sealed with foil paper and incubated for $1 \mathrm{~h}$ at room temperature. After the removal of the seal, the contents of the well were aspirated, each well was washed 3 times with $300 \mu \mathrm{L}$ of $1 \times$ washing solution. After the last wash, the remaining $1 \times$ washing solution was removed by decanting, the plate was inverted and then blotted against clean paper towels to remove excess liquid. A $100 \mu \mathrm{L}$ of malaria anti-IgG conjugate was added into the wells and incubated for $30 \mathrm{~min}$ at room temperature. Subsequently, $100 \mu \mathrm{L}$ of Tetramethylbenzidine (TMB) substrate solution was added into the wells and incubated at exactly $15 \mathrm{~min}$ at room temperature in the dark. Stop solution $(100 \mu \mathrm{L})$ was added into the wells in the same order and at the same rate as for the TMB substrate solution. It was noted that any blue color developed during the incubation stage turned yellow. The absorbance of the specimen was measured at $450 \mathrm{~nm}$ within $30 \mathrm{~min}$ of the addition of stop solution.

\section{Calculation and interpretation of results for ELISA}

For the result calculation, the mean background subtracted absorbance for each sample was calculated and was compared to the mean cutoff control value. The cutoff control value is the mean absorbance value of the cutoff control wells.

$$
\begin{aligned}
\text { Results in Standard Units } & =\frac{\text { Patients }(\text { mean }) \text { absorbance value }}{\text { Cut }- \text { off }} \times 100 \\
& =\text { Standard Units }
\end{aligned}
$$

Samples were considered to give a positive signal if the absorbance value is $>10 \%$ over the cutoff value. Samples with an absorbance value of $<10 \%$ below the cutoff value were considered as negative.
Data processing and analysis

The data were analyzed using SPSS version 23.0 statistical software package. The age of participants was categorized into three groups - 6 months-5 years, 6-11 years, 12-17 years and a control group of $>18$ years. Chi square analysis was used to determine the correlation between antibody responses to malaria antigens. Mann-Whitney and Kruskal-Wallis tests were used to test for the differences in proportions and determine relationships between categorical variables. Correlation coefficient between IgG concentrations and age was determined. A twotailed $\mathrm{p}<0.05$ was considered statistically significant.

\section{RESULTS}

Demographic and clinical features of the study participants A total of 93 participants were included in the study with 45 (48.38\%) males and 48 (51.61\%) females. From this, 36 (38.70\%) were below 5 years, $29(31.20 \%)$ were between the age of 6 and 11 years, 23 $(24.80 \%)$ aged 12 and 17 years, and a control group of $>18$ years with 5 (5.30\%) (Table 1). Meanwhile, 84 (90.32\%) were infected with P. falciparum and observed positive by microscopy.

\section{IgG antibody response to $P$. falciparum infection}

From the study, generally, there was a high seroprevalence of IgG antibody against $P$. falciparum antigens tested with 69 (74.20\%). The frequency of a non-reactive response to an antigen was 17 (18.27\%). There was no production of antibody, which was an indication of the absence of $P$. falciparum. Furthermore, an indeterminate group - the grey zone (may occur either due to the patient recently infected with the $P$. falciparum pathogen or possess the low strength of the pathogen), recorded 7 (7.52\%). Meanwhile, from the total of 93 samples exposed to ELISA, $84(90.32 \%)$ of the samples were infected with P. falciparum whilst, 9 (9.67\%) tested negative with microscopy. Interestingly, of the nine cases (9.67\%) tested negative with microscopy, more than half of the samples (5) produced IgG antibody against the antigens (Table 2). In contrast, cases with P. falciparum infection recorded higher specific IgG antibody responses 64 (68.81\%) as compared to negative $P$. falciparum cases, suggesting a strong relationship between production of specific antibodies and $P$. falciparum transmission, rather than protective immunity. Analysis using the Mann-Whitney $U$-test revealed a non-significant difference ( $>0.05$ ) in IgG antibody response to P. falciparum infection between negative $P$. falciparum cases and $P$. falciparum infected cases. In addition, a non-significant negative correlation between the negative and positive P. falciparum parasite and the production of antibody IgG was recorded at $\mathrm{p}>0.05$.

\section{IgG antibody response to $P$. falciparum $\mathrm{PD}$}

The highest seroprevalence of IgG antibody response to $P$. falciparum antigen was detected in plasma samples with high Parkinson's disease $9(90.00 \%)$. This was then followed by those with low PD $13(81.25 \%)$, and the least observed seroprevalence of $P$. falciparum IgG antibody was observed in samples with moderate PD 42 (72.41\%) (Table 3).

The differences in the seroprevalence of $P$. falciparum IgG antibody were not significant $(p>0.05)$ between all the PD (low, moderate, and high parasitemia) and non-significant association exists between them ( $p>0.05)$. For variation between the IgG antibody and the PD, significant difference ( $\mathrm{p}>0.05$ ) was not observed between $P$. falciparum infected erythrocyte and PD using Analysis of Variance. Furthermore, Kruskal-Wallis $H$ test was used to determine variations in IgG response

Table 1: Demographic features of the study participants

\begin{tabular}{llll}
\hline Age/Sex & Male (\%) & Female (\%) & Total (\%) \\
\hline 6 month-5 year & $21(47.00)$ & $15(31.30)$ & $36(38.70)$ \\
6 year-11 year & $11(24.00)$ & $18(37.50)$ & $29(31.20)$ \\
12 year-17 year & $10(22.00)$ & $13(27.10)$ & $23(24.80)$ \\
>18 year (control) & $3(7.00)$ & $2(4.10)$ & $5(5.30)$ \\
Total & $45(100)$ & $48(100)$ & $93(100)$ \\
\hline
\end{tabular}


between the different categories of PD, and a statistically non-significant difference was observed in all the categories of PD ( $p>0.05)$.

Fig. 1 shows a boxplot of the distribution of IgG absorbance values at $450 \mathrm{~nm}$ in P. falciparum for PD. The horizontal bars in the middle of each box indicate the mean percentage of OD. The top and bottom of each box represent the upper and lower quartiles, respectively.

IgG antibody responses to $P$. falciparum in relation to sex and age From this study, it was recorded that both the male and female category had prevalence of reactive samples, that is, samples that produced IgG antibody against $P$. falciparum antigen, and were quite higher in male category with $35 / 45(77.77 \%)$ and $34 / 48$ (70.83\%), respectively. The highest seroprevalence was observed in older children. The frequency of a non-reactive response to an antigen was $17 / 93(18.27 \%)$ with $8 / 45(17.77 \%)$ in male and $9 / 48(18.75 \%)$ from the female category. Furthermore, an indeterminate group - the grey zone also recorded a total $7 / 93$ cases $(7.52 \%)$ with male category having $2 / 45(4.44 \%)$ and female category with $5 / 48(10.41 \%)$. This effect could be as a result that either the patients were recently infected with the $P$. falciparum pathogen or they possess the low strength of the pathogen (Table 4).

Analysis using the Mann-Whitney U-test, however, revealed IgG antibody response to $P$. falciparum infection in the male was significantly different from that of the female category $(\mathrm{p}<0.05)$. In addition, the differences in the seroprevalence of $P$. falciparum IgG antibody response to the antigen were not significant $(\mathrm{p}>0.05)$ with age and no significant association exists between them. Furthermore, Kruskal-Wallis H test

Table 2: Immunoglobulin G antibody response to $P$. falciparum infection

\begin{tabular}{llll}
\hline $\begin{array}{l}\text { Antibody IgG } \\
\text { response }\end{array}$ & $\begin{array}{l}\text { P. falciparum } \\
\text { negative (\%) }\end{array}$ & $\begin{array}{l}\text { P.falciparum } \\
\text { positive (\%) }\end{array}$ & Total (\%) \\
\hline Non-reactive $(<9)$ & $3(3.22)$ & $14(15.05)$ & $17(18.27)$ \\
Grey zone $(9-11)$ & $1(1.07)$ & $6(6.45)$ & $7(7.52)$ \\
Positive $(>11)$ & $5(5.37)$ & $64(68.81)$ & $69(74.20)$ \\
Total & $9(9.67)$ & $84(90.32)$ & $93(100)$ \\
\hline
\end{tabular}

P. falciparum: Plasmodium falciparum

Table 3: Immunoglobulin G antibody response to $P$. falciparum parasite density

\begin{tabular}{|c|c|c|c|c|}
\hline \multirow[t]{2}{*}{ PD } & \multirow{2}{*}{$\begin{array}{l}\text { No. } \\
\text { exam. }\end{array}$} & \multicolumn{3}{|c|}{ Antibody IgG response } \\
\hline & & $\begin{array}{l}\text { Non-reactive } \\
<9(\%)\end{array}$ & $\begin{array}{l}\text { Grey zone } \\
9-11(\%)\end{array}$ & $\begin{array}{l}\text { Positive } \\
>11(\%)\end{array}$ \\
\hline Negative & 9 & $3(33.33)$ & $1(11.11)$ & $5(55.55)$ \\
\hline Low PD $(<1000 / \mu \mathrm{l})$ & 16 & $2(12.50)$ & $1(6.25)$ & $13(81.25)$ \\
\hline $\begin{array}{l}\text { Moderate PD } \\
(1001-10,000 / \mu \mathrm{l})\end{array}$ & 58 & $11(18.96)$ & $5(8.62)$ & $42(72.41)$ \\
\hline $\begin{array}{l}\text { High PD } \\
(>10,001 / \mu \mathrm{l})\end{array}$ & 10 & $1(10.00)$ & $0(0.00)$ & $9(90.00)$ \\
\hline Total & 93 & 17 (18.27) & $7(7.52)$ & $69(74.19)$ \\
\hline
\end{tabular}

P. falciparum: Plasmodium falciparum, PD: Parasite density was used to test for variation between the age groups and it showed a non-significant difference in IgG antibody response between the age groups $(\mathrm{p}>0.05)$.

Fig. 2 shows a boxplot of the distribution of IgG absorbance values at $450 \mathrm{~nm}$ in $P$. falciparum for male and female. The mean absorbance recorded was $45 \mathrm{SU}$ and $25 \mathrm{SU}$; the lower quartiles of $5 \mathrm{SU}$ and $5 \mathrm{SU}$; and an upper quartiles of $65 \mathrm{SU}$ and $63 \mathrm{SU}$ for both male and female groups, respectively. Meanwhile, Fig. 3 also showed a box plot of the distribution of IgG absorbance values at $450 \mathrm{~nm}$ in P. falciparum for different cohorts. The horizontal bars for mean absorbance were recorded as $25 \mathrm{SU}, 32 \mathrm{SU}, 50 \mathrm{SU}$, and $48 \mathrm{SU}$; the lower quartiles of $2 \mathrm{SU}$, $4 \mathrm{SU}, 5 \mathrm{SU}$, and $24 \mathrm{SU}$; and an upper quartiles of $70 \mathrm{SU}, 67 \mathrm{SU}, 69 \mathrm{SU}$, and $68 \mathrm{SU}$ for age groups 6 months- 5 years, 6-11 years, 12-17 years, and $>18$ years, respectively.

\section{DISCUSSION}

In this study, the relationship between IgG antibody responses to $P$. falciparum parasite populations in children with malaria infections was assessed in Minna, Niger State, North-Central Nigeria. There was a high seroprevalence of antibodies in general, against $P$. falciparum antigens tested with about $74 \%$. The findings from this study were supported by the previous work which reported a high seroprevalence and protective role of antibodies in the endemic Dielmo area [12] (Diop et al., 2014), and also in another study by Nazareth et al. (2017) [13], where a synthetic malaria antigen was used, with about three-quarters (78.80\%) of the participants positive for total IgG antibodies to the antigen (AS202.11 peptide).

Samples detected by microscopy with $P$. falciparum had higher specific antibody IgG responses compared to negative $P$. falciparum samples, suggesting a strong relationship between production of specific antibodies and $P$. falciparum transmission, rather than protective immunity, in other words, the studied specific antibody IgG responses appeared thus to be associated with malaria infection rather than antimalarial protective immunity and this could also be a proof that the antibody served as a potential markers of both exposure to P. falciparum and protection against disease. This was discussed by Sarr et al.

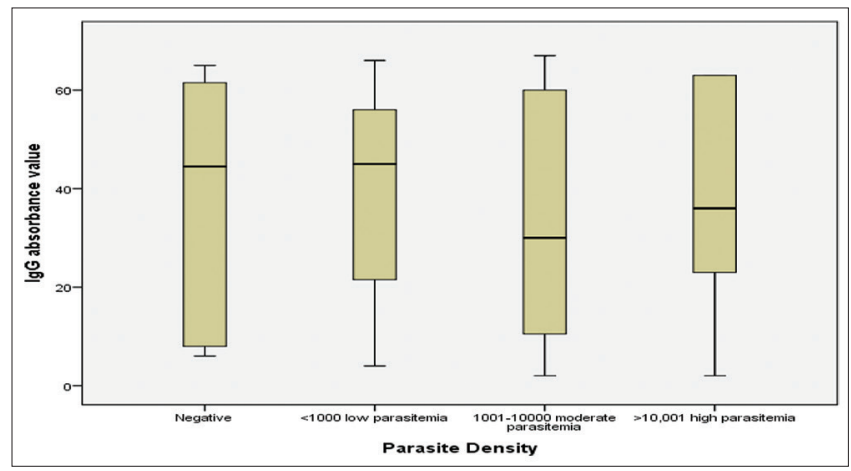

Fig. 1: Boxplot of the distribution of immunoglobulin G absorbance values at $450 \mathrm{~nm}$ in Plasmodium falciparum for parasite density

Table 4: Immunoglobulin G antibody to $P$. falciparum in relation to sex and age

\begin{tabular}{|c|c|c|c|c|c|c|c|c|c|}
\hline \multirow{2}{*}{$\begin{array}{l}\text { Sex } \\
\text { Age/IgG response }\end{array}$} & \multicolumn{3}{|l|}{ Overall } & \multicolumn{3}{|l|}{ Male } & \multicolumn{3}{|l|}{ Female } \\
\hline & $\begin{array}{l}\text { Non-reactive } \\
<9(\%)\end{array}$ & $\begin{array}{l}\text { Grey zone } \\
\text { 9-11 (\%) }\end{array}$ & $\begin{array}{l}\text { Positive } \\
>11(\%)\end{array}$ & $\begin{array}{l}\text { Non-reactive } \\
<9(\%)\end{array}$ & $\begin{array}{l}\text { Grey zone } \\
\text { 9-11 (\%) }\end{array}$ & $\begin{array}{l}\text { Positive } \\
>11(\%)\end{array}$ & $\begin{array}{l}\text { Non-reactive } \\
<9(\%)\end{array}$ & $\begin{array}{l}\text { Grey zone } \\
\text { 9-11 (\%) }\end{array}$ & $\begin{array}{l}\text { Positive } \\
>11(\%)\end{array}$ \\
\hline 6 month-5 year & $9(25.00)$ & $3(8.33)$ & $24(66.66)$ & $5(23.80)$ & $2(9.50)$ & $14(66.66)$ & $4(26.66)$ & $1(6.66)$ & $10(66.66)$ \\
\hline 6 year-11 year & $4(13.80)$ & $4(13.80)$ & $21(72.41)$ & $1(9.09)$ & $0(0.00)$ & $10(90.90)$ & $3(16.66)$ & $4(22.22)$ & $11(61.11)$ \\
\hline 12 year-17 year & $4(17.40)$ & $0(0.00)$ & $19(82.60)$ & $2(20.00)$ & $0(0.00)$ & $8(80.00)$ & $2(15.38)$ & $0(0.00)$ & $11(84.61)$ \\
\hline$>18$ year (control) & $0(0.00)$ & $0(0.00)$ & $5(100.00)$ & $0(0.00)$ & $0(0.00)$ & $3(100.00)$ & $0(0.00)$ & $0(0.00)$ & $2(100.00)$ \\
\hline
\end{tabular}

P. falciparum: Plasmodium falciparum 


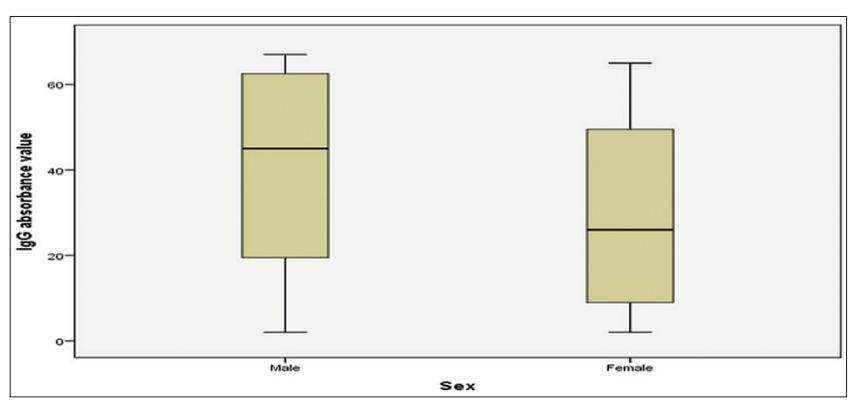

Fig. 2: Boxplot of the distribution of immunoglobulin G absorbance values at $450 \mathrm{~nm}$ in Plasmodium falciparum infection for male and female

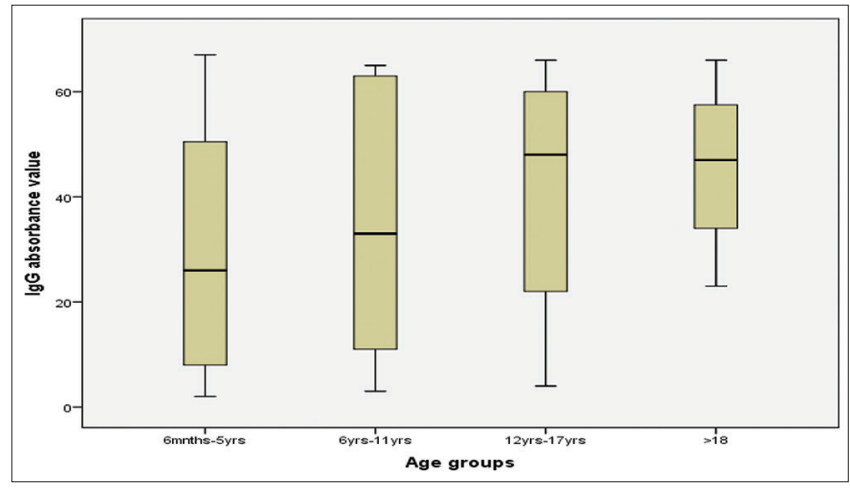

Fig. 3: Boxplot of the distribution of immunoglobulin G absorbance values at $450 \mathrm{~nm}$ in Plasmodium falciparum infection for different age groups

(2007) [14], in their study which states that children with P. falciparum infection had higher specific antibody responses compared to negative infection children.

Meanwhile, of the $9 \%$ microscopically negative P. falciparum samples, more than half produced antibodies to P. falciparum antigens. This could also be a proof of a sub-microscopic parasite and is evident for boosting immune responses by these sub-microscopic parasites. This observation was in line with other studies from low transmission settings $[15,16]$, but was not in agreement with a previous study in an intense malaria transmission setting in Uganda [17], and also in Kenya, Lake Victoria [18].

However, associations between antibody responses to $P$. falciparum antigen and the risk of $P$. falciparum infection have shown to be statistically non-significant. This observation was inconsistent in multiple studies [19]. Potential reasons for these inconsistencies may include differences in the intensity and stability of transmission, allelic variation of specific antigens, and IgG subclass switching [3].

The influence of microscopically detectable PD to prevalence of antibody responses in this study shows that samples with high PD showed the highest seroprevalence, with $90 \%$ that produced IgG antibody against the P. falciparum antigens. This was then followed by samples with low PD with $81 \%$ and the least seroprevalence in this category was found in samples with moderate PD 72\%. Contrary to the previous findings in Lake Victoria, Kenya by Idris et al. (2017) [18], an increase IgG antibody levels was observed with PD. Furthermore, in line with the previous studies by Idris et al. (2017) [18], the differences in the seroprevalence of $P$. falciparum antibody from this study were not significant $(\mathrm{p}>0.05)$ between PD (low, moderate, and high parasitemia) and no significant association exists between them; and this was also observed in a similar work conducted by Ismail et al. (2017) [20], which states that there was no correlation between initial parasitemia and the presence of either IgG or IgM with any of the tested antigens, as measured by ELISA. The result obtained from this study was quite similar with a previous work conducted between two villages by Sarr et al. (2007) [14], that states that a correlation was observed between the intensity of malaria infection (number of P. falciparum parasite/ $\mu$ l of blood) and Antibody responses in Mboula ( $\mathrm{r}=0.332$, $\mathrm{p}=0.02)$, whereas in Gankette Balla the correlation ( $\mathrm{r}=0.047)$ was not significant.

Seroprevalence to $P$. falciparum IgG antibody increased with age, though no statistical significant differences between them $(p>0.05)$. There were conflicting results as to whether the production of antibody as a result of $P$. falciparum infection increases or decreases with age, from the previous studies. Nazareth et al. (2017) [13] observed a statistical differences in the seropositivity between the youngest ( $\leq 12$ years) and the other age categories; but did not differ significantly between the middle age (13-40 years) and the older ( $>40$ years) categories. Niang et al. (2017) [21] observed a low (47.19\%) and high (89.45\%) seroprevalences to Pfsch07/03 ( $P$. falciparum schizonts) antibodies, respectively, in children and older adults. This was further elucidated from this study where all control samples (which were adults) produced antibodies against $P$. falciparum antigens and thus could also be as a result of more previous exposures to malaria infection in the adults. In contrast, it was also reported from a previous study that specific IgG responses increased progressively in children aged from 1 to 5 years and then stay high until eight. In another study by Idris et al. (2017) [18], it states that P. falciparum antibody prevalence increased with age. In the present study, the fact that seroprevalence to P. falciparum IgG antibody was higher in older children and even adults, P. falciparum appears to be a factor of variation of the age-dependent development of anti-malarial IgG responses.

Seroprevalence to $P$. falciparum antibody IgG observed in male was quite higher as compared to the female category $(77.77 \%$ and $70.83 \%$, respectively) with statistical significant difference between them, indicating non similar exposure (i.e., males have more exposure to the parasite) between the two groups.

\section{CONCLUSION}

Findings from this study revealed differences in seroprevalence of age and sex, and it was categorically discovered that the male had higher risk of exposure to the parasite. The seroprevalence of $P$. falciparum antigen is non-dependent on the age of the child. However, cases with microscopically detectable high PD (severe malaria) observed the highest seroprevalence, and this suggests that immune responses are more stable in this category. Similarly, an evidence (of more than 50\%) was found for a boosting of immune responses by sub-microscopic parasite from this study and consequently, sub-microscopic infections will provide an antigenic stimulus to maintain immune responses.

This study has several limitations: The study is a cross-sectional, and it provides limited information about the participants. In addition, the convenience sampling method used in this study has inherent selection bias. The survey was conducted in healthcare facilities, meaning that children out of the healthcare facilities and asymptomatic cases were not represented, though this approach is still valid to obtaining an estimate of seroprevalence of the parasite. The outpatient department of the healthcare facilities was visited by mostly children under the age of 5 , which means that older children were under sampled. This study warrants further investigation in a wider population inclusive of asymptomatic individuals to have an inclusive picture of the dynamics of responses to Ig.

\section{CONFLICT OF INTEREST}

The authors declare no conflict of interest. 


\section{ACKNOWLEDGMENT}

We thank the Director Chanchaga Primary Healthcare Hajiya Fatima Garba, and her staff, Aishatu Mustapha (of Tunga PHC), Mr. Hamza (Oldairport PHC), Mr. Salihu (Limawa FSP), Mr Habib (Gwari-road PHC); community leader of MAWIS Mall Isah Yahya; and the study participants and their parents/guardians. We sincerely thank Mr. Zakari Jibrin for his moral and spiritual support. We really appreciate the team at General Hospital Minna, Mr Abdullahi Habib Etsugaie, Mr Abel Nsude Okechukwu and Mr Abdullahi Mohammed; and also staff of DNA Lab, Kaduna.

\section{REFERENCES}

1. World Health Organization. World Malaria Report. Geneva, Switzerland: World Health Organization; 2015.

2. World Health Organization. Statistics Profile, Nigeria 2015. Geneva, Switzerland: World Health Organization; 2015. Available from: http:// www.who.int/gho/countries/nga.pdf. [Last accessed on 2015 Jan 21]

3. Marsh K, Kinyanjui S. Immune effector mechanisma in malaria. Parasite Immunol 2006;28:51-60.

4. Doolan DL, Dobano C, Baird JK. Acquired immunity to malaria. Clin Microbiol Rev 2009;22:13-36.

5. Richards S, Beeson JG. The future for blood-stage vaccines against malaria. Immunol Cell Biol 2009;87 Suppl 5:377-90.

6. Smith T, Felger I, Tanner M, Beck HP. Premunition in Plasmodium falciparum infection: Insights from the epidemiology of multiple infections. Trans R Soc Trop Med Hyg 1999;93 Suppl 1:59-64.

7. Magesa SM, Mdira KY, Babiker HA, Alifrangis M, Färnert A, Simonsen PE, et al. Diversity of Plasmodium falciparum clones infecting children living in a holoendemic area in North-Eastern Tanzania. Acta Trop 2002;84:83-92.

8. Hamad AA, El Hassan IM, El Khalifa AA, Ahmed GI, Abdelrahim SA, Theander TG, et al. Chronic Plasmodium falciparum infections in an area of low intensity malaria transmission in the Sudan. Parasitol 2000;120 Suppl 5:447-56.

9. Mosadomi W. 19,000 under-5 Children Die of Malaria Annually in Niger State. Vanguard Newspaper. April 29, 2016 2:02 am; 2016.

10. Omalu IC, Mgbemena C, Mgbemena A, Ayanwale V, Olayemi IK Lateef A, et al. Prevalence of congenital malaria in Minna, North Central Nigeria. J Trop M 2012;2012:274142.

11. Sumbele IU, Sama SD, Kimbi HK, Taiwe GS. Malaria, moderate to severe anaemia, and malarial anaemia in children at presentation to hospital in the mount Cameroon area: A cross-sectional study. Anemia 2016;2016:5725634.

12. Diop F, Richard V, Diouf B, Sokhna C, Diagne N, Trape JF, et al. Dramatic declines in seropositivity as determined with crude extracts of Plasmodium falciparum schizonts between 2000 and 2010 in Dielmo and Ndiop, Senegal. Malar J 2014;13:83.

13. Nazareth R, Horumpende P, Sonda T, Ndaro A, Mollel E, Paul E, et al. Naturally acquired antibody responses to a synthetic malaria antigen AS202.11. J Trop Med 2017;2017:6843701.

14. Sarr JB, Remoue F, Samb B, Dia I, Guindo S, Sow C, et al. Evaluation of antibody response to Plasmodium falciparum in children according to exposure of Anopheles gambiae s.l or Anopheles funestus vectors. Malar J 2007;6:117.

15. Shekalaghe S, Alifrangis M, Mwanziva C, Enevold A, Mwakalinga S, Mkali $\mathrm{H}$, et al. Low density parasitaemia, red blood cell polymorphisms and Plasmodium falciparum specific immune responses in a low endemic area in northern Tanzania. BMC Infect Dis 2009;9:69.

16. Giha HA, Nasr A, Iriemenam NC, Balogun HA, Arnot D, Theander TG, et al. Age-dependent association between IgG2 and IgG3 subclasses to Pf332-C231 antigen and protection from malaria, and induction of protective antibodies by sub-patent malaria infections, in Daraweesh. Vaccine 2010;28:1732-9.

17. Proietti C, Pettinato DD, Kanoi BN, Ntege E, Crisanti A, Riley EM, et al. Continuing intense malaria transmission in Northern Uganda. Am J Trop Med Hyg 2011;84:830-7.

18. Idris ZM, Chan CW, Kongere J, Hall T, Logedi J, Gitaka J, et al. Naturally acquired antibody response to Plasmodium falciparum describes heterogeneity in transmission on islands in Lake Victoria. Nat Res J 2017;7:9123.

19. Fowkes FJ, Richards JS, Simpson JA, Beeson JG. The relationship between anti-merozoite antibodies and incidence of Plasmodium falciparum malaria: A systematic review and meta-analysis. PLoS Med 2010;7:e1000218

20. Ismail HA, Ribacke U, Reiling L, Normark J, Egwang T, Kironde F, et al. Acquired antibodies to merozoite antigens in children from Uganda with uncomplicated or severe Plasmodium falciparum malaria. Clin Vaccine Immunol 2017;156:13.

21. Niang M, Niass O, Diagne N, Sarr FD, Faye MM, Diop F, et al. Temporal analysis of IgG antibody responses to Plasmodium falciparum antigens in relation to changing malaria epidemiology in a West African setting. Malar J 2017;16:283. 